\title{
Gastrointestinal iron excretion and reversal of iron excess in a mouse model of inherited iron excess
}

Haematologica 2019

Volume 104(4):678-689

\section{Correspondence: \\ THOMAS BARTNIKAS \\ thomas_bartnikas@brown.edu \\ Received: May 22, 2018. \\ Accepted: November 7, 2018 \\ Pre-published: November 8, 2018.}

doi:10.3324/haematol.2018.198382

Check the online version for the most updated information on this article, online supplements, and information on authorship \& disclosures: www. haematologica.org/content/104/4/678

(C)2019 Ferrata Storti Foundation

Material published in Haematologica is covered by copyright. All rights are reserved to the Ferrata Storti Foundation. Use of published material is allowed under the following terms and conditions:

https://creativecommons.org/licenses/by-nc/4.0/legalcode. Copies of published material are allowed for personal or internal use. Sharing published material for non-commercial purposes is subject to the following conditions:

https://creativecommons.org/licenses/by-nc/4.0/legalcode, sect. 3. Reproducing and sharing published material for commercial purposes is not allowed without permission in writing from the publisher.

\author{
Courtney J. Mercadante, ${ }^{1}$ Milankumar Prajapati, ${ }^{1}$ Jignesh H. Parmar, ${ }^{2}$ \\ Heather L. Conboy, ${ }^{1}$ Miriam E. Dash, ${ }^{1}$ Michael A. Pettiglio, ${ }^{1}$ Carolina Herrera, ${ }^{1}$ \\ Julia T. Bu, ${ }^{1}$ Edward G. Stopa, ${ }^{1}$ Pedro Mendes $^{2}$ and Thomas B. Bartnikas ${ }^{1}$ \\ ${ }^{1}$ Department of Pathology and Laboratory Medicine, Brown University, Providence, RI and \\ ${ }^{2}$ Center for Quantitative Medicine and Department of Cell Biology, University of \\ Connecticut School of Medicine, Farmington, CT, USA
}

\section{ABSTRACT}

1 The current paradigm in the field of mammalian iron biology states that body iron levels are determined by dietary iron absorption, not by iron excretion. Iron absorption is a highly regulated process influenced by iron levels and other factors. Iron excretion is believed to occur at a basal rate irrespective of iron levels and is associated with processes such as turnover of intestinal epithelium, blood loss, and exfoliation of dead skin. Here we explore iron excretion in a mouse model of iron excess due to inherited transferrin deficiency. Iron excess in this model is attributed to impaired regulation of iron absorption leading to excessive dietary iron uptake. Pharmacological correction of transferrin deficiency not only normalized iron absorption rates and halted progression of iron excess but also reversed body iron excess. Transferrin treatment did not alter the half-life of ${ }^{59} \mathrm{Fe}$ in mutant mice. ${ }^{59} \mathrm{Fe}$-based studies indicated that most iron was excreted via the gastrointestinal tract and suggested that iron-loaded mutant mice had increased rates of iron excretion. Direct measurement of urinary iron levels agreed with ${ }^{59} \mathrm{Fe}$-based predictions that urinary iron levels were increased in untreated mutant mice. Fecal ferritin levels were also increased in mutant mice relative to wild-type mice. Overall, these data suggest that mice have a significant capacity for iron excretion. We propose that further investigation into iron excretion is warranted in this and other models of perturbed iron homeostasis, as pharmacological targeting of iron excretion may represent a novel means of treatment for diseases of iron excess.

\section{Introduction}

Iron is an essential nutrient but toxic when present in excess. While body iron levels are determined in theory by a balance between absorption and excretion, the current paradigm in the field of iron biology states that the rate of absorption determines iron levels. ${ }^{1-5}$ Iron absorption is an orchestrated process regulated prominently by hepcidin, a hormone synthesized mainly by the liver which inhibits iron export from duodenal enterocytes and other types of cells. Hepcidin expression is suppressed by anemia, leading to increased absorption of iron, and stimulated by iron excess and inflammation, leading to decreased absorption. Hepcidin deficiency is central to common inherited diseases of iron excess such as hereditary hemochromatosis and $\beta$-thalassemia. Hemochromatosis is caused by mutations in genes required for hepcidin expression. ${ }^{6,7} \beta$-thalassemia is caused by $\beta$-globin mutations leading to ineffective erythropoiesis, anemia, and hepcidin deficiency. ${ }^{8-10}$

In contrast to iron absorption, iron excretion is presumed to occur at a basal rate irrespective of iron deficiency or excess..$^{1-5}$ Excretion is believed to reflect processes such as turnover of intestinal epithelium, blood loss, and exfoliation of dead skin. Renal iron excretion is considered a negligible factor in iron homeostasis. The liver 
is also believed to contribute minimally to elimination of iron from the body, despite the fact that hepatobiliary excretion is a prominent means of excretion of other metals such as manganese and copper.

In this study, we investigated iron excretion in $\operatorname{Tr} f^{i p x} \times \operatorname{lp} x$ mice, a model of inherited deficiency of the serum ironbinding protein transferrin. ${ }^{11}$ These mice develop anemia because transferrin is essential for iron delivery to erythroid precursors. They also develop iron excess because transferrin is essential for hepcidin expression. We and others previously observed that treatment of adult $\operatorname{Tr} f^{i p x / h p}$ mice with transferrin for 2 to 3 weeks not only corrected anemia and hepcidin deficiency but also lowered liver iron concentrations. ${ }^{12,13}$ Here we exploit the latter observation to assess the effect of iron excess on iron excretion and to identify routes of iron excretion using short- and long-term transferrin treatment and radioisotopic studies. Our data suggest that the view that iron levels are dictated solely by absorption needs to be reconsidered. They also suggest that non-gastrointestinal routes of excretion, such as exfoliation of skin, play a minimal role in iron homeostasis.

\section{Methods}

\section{Animals and transferrin treatment}

Studies were approved by the Animal Care and Use Committee at Brown University. Mice were maintained on LabDiet 5010 containing $270 \mathrm{ppm}$ iron. BALB/cJ $\operatorname{Trf}^{\mathrm{f} / \mathrm{t}}$ and $\operatorname{Trf}^{\mathrm{fp} \times \mathrm{p} / \mathrm{p} x}$ mice were generated by crossing $\operatorname{Tr}^{f / h p x}$ mice, which were intermittently backcrossed to BALB/cJ mice (Jackson Laboratories). To ensure survival of $\operatorname{Tr}^{f_{i p x} / h h_{x}}$ mice after weaning, pups were injected intraperitoneally with $3 \mathrm{mg}$ human transferrin (Roche/Sigma) 2 days after birth, then once a week until weaning at 3 weeks of age. For all experiments, mice were aged from weaning to 2 months without transferrin injections, then some were injected intraperitoneally with $3 \mathrm{mg}$ human transferrin three times a week as required for specific experiments.

\section{Non-radioactive sample harvesting and analysis}

Details on the collection of blood and tissues from mice, transferrin immunoblots, measurement of hemoglobin, hepcidin, and RNA levels, tissue staining, and metal analysis are provided in the Online Supplementary Methods. Body and tissue iron levels were measured by inductively coupled plasma absorption emission spectrometry (ICP-AES) of acid-digested tissues in the Environmental Chemistry Facility at Brown University.

\section{${ }^{59} \mathrm{Fe}$ treatments, sample harvesting and analysis}

To assess absorption, mice were fasted in metabolic cages (Tecniplast) with access to water for $4 \mathrm{~h}$, then gavaged with 10 $\mu \mathrm{Ci}^{59} \mathrm{FeCl}_{3}$ (Perkin Elmer) and $6 \mu \mathrm{g} \mathrm{FeCl}{ }_{3}$ in $100 \mu \mathrm{L} 1 \mathrm{M}$ ascorbic acid. ${ }^{14}$ The mice were then housed in metabolic cages with food and water for 16 h. ${ }^{59} \mathrm{Fe}$ levels were measured in bodies, feces, and urine using a Triathler Gamma Counter and external NaI well-type crystal detector (Hidex). To measure body ${ }^{59} \mathrm{Fe} \mathrm{levels,}$ mice were anesthetized with isoflurane, placed nose-first into a $50 \mathrm{~mL}$ conical tube positioned vertically in the detector, and radioactivity was counted. Background counts were subtracted from all counts. Percent ${ }^{59} \mathrm{Fe}$ absorption was calculated by expressing the sum of body and urine ${ }^{59} \mathrm{Fe}$ levels as a percent of the sum of body, fecal, and urinary ${ }^{59} \mathrm{Fe}$ levels.

To assess excretion, mice from the absorption studies were housed individually in regular cages for 2 months. Transferrin treatment was continued as before when indicated. Bedding was changed once a week. Some mice were housed with a 'buddy' mouse not administered ${ }^{59} \mathrm{Fe}$. Every 1 to 2 weeks, body ${ }^{59} \mathrm{Fe}$ levels of all the mice were measured. Buddy mouse ${ }^{59} \mathrm{Fe}$ levels never exceeded background, suggesting that coprophagy was not prominent. Details on the conversion of body ${ }^{59} \mathrm{Fe}$ counts to ${ }^{59} \mathrm{Fe}$ half-lives and excretion rates are given in the Online Supplementary Methods.

To identify routes of ${ }^{59} \mathrm{Fe}$ excretion, mice were housed overnight for $16 \mathrm{~h}$ in metabolic cages at least three times during the excretion study. Feces and urine were analyzed for ${ }^{59} \mathrm{Fe}$ levels by gamma counting then for iron and ferritin levels using ICPAES and enzyme-linked immunosorbent assay (ELISA) as described in the Online Supplementary Methods.

\section{Mathematical modeling}

The mathematical modeling of iron levels is described in the Online Supplementary Methods. A manuscript on the model is currently under review and a preprint version of the paper is available. ${ }^{15}$

\section{Statistical analysis}

Statistical significance $(P<0.05)$ was calculated by a two-tailed $t$-test or one- or two-way analysis of variance (ANOVA) with a Holm-Sidak post-hoc test using Sigmaplot. Pearson correlations were also measured using Sigmaplot.

\section{Results}

\section{Short-term transferrin treatment reduces tissue iron excess in $T r f^{f p x / h p x}$ mice}

Short-term transferrin treatment of adult $\operatorname{Tr}^{f i p \times t h p x}$ mice decreases liver iron concentrations. ${ }^{12,13}$ To investigate this phenomenon further, we first determined whether a 2 week course of transferrin treatment in 2-month old $\operatorname{Tif}^{f_{p \times x} \times \operatorname{lpx} x}$ mice altered iron concentrations in organs other than the liver. As expected, transferrin treatment increased serum transferrin, blood hemoglobin, and serum hepcidin levels in mutant mice (Figure 1A-C). Treatment also normalized Fam132b RNA levels in the spleen, a site of

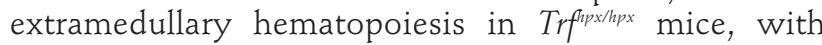
Fam 132b encoding erythroferrone, which is an inhibitor of hepcidin that is expression expressed by erythroid precursors (Figure 1D). ${ }^{16}$ Transferrin treatment also corrects severe splenomegaly in mutant mice. ${ }^{12}$ Untreated $T_{i f} f^{p_{x} \times h h_{x}}$ mice accumulated iron largely in the liver and pancreas, specifically in hepatic periportal regions and exocrine pancreas, and to a lesser extent in the kidneys, heart, and other tissues (Figure 1E). ${ }^{11}$ While Trf ${ }^{\prime / 4}$ mice had stainable iron in the red pulp of the spleen, untreated Trf fipshpx mice had splenic iron deficiency and a paucity of stainable iron. We attribute this to the fact that hepcidin also inhibits macrophage iron export - hepcidin deficiency in mutant mice leads to persistent iron export from red pulp macrophages scavenging iron-poor red blood cells. Transferrin treatment decreased iron concentrations and tissue iron staining in the liver, pancreas, and kidneys but not in the heart or duodenum and increased iron concentrations and tissue iron staining in the spleen (Figure 1E and Figure 2). Stainable iron was also detectable in duodenal smooth muscle in untreated and treated Tr $f^{\text {ipx } x h p x}$ mice but in duodenal enterocytes only in treated mutant mice (Figure 2B,C). Overall, transferrin treatment decreased iron concentrations in multiple organs in Tr $r^{f i p x h p x}$ mice. 
Long-term transferrin treatment corrects body iron excess in $T r f^{f i p / h p x}$ mice

Several scenarios could explain decreased iron concen-

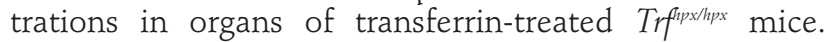
Given the severity of anemia in untreated $\operatorname{Tr} r^{f i p \times / h x}$ mice, the increase in hemoglobin levels in treated mutant mice should require mobilization of a significant amount of iron from the liver and other organs to the bone marrow. We estimated that $0.30 \mathrm{mg}$ of iron were mobilized from the liver and pancreas during the first 2 weeks of treatment and that the anemia in untreated mutant mice corresponded to a deficit of $0.475 \mathrm{mg}$ of hemoglobin iron

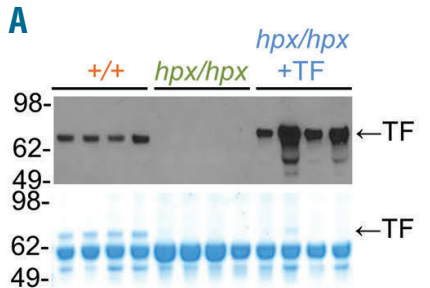

E
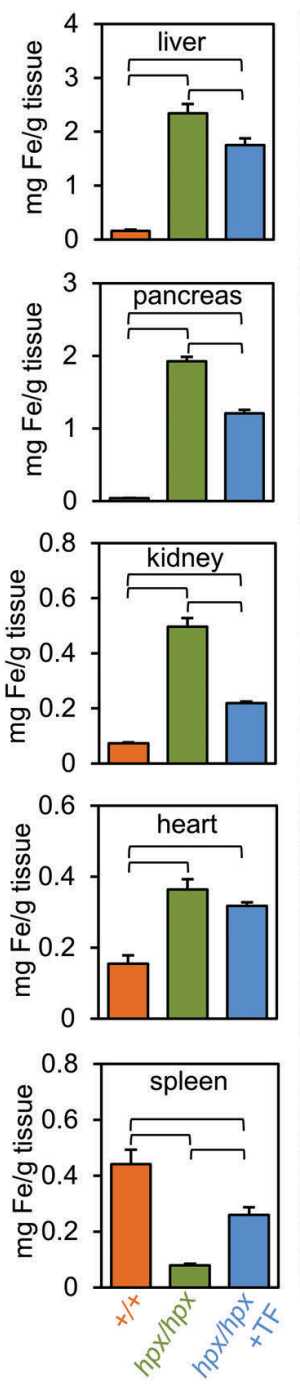

B

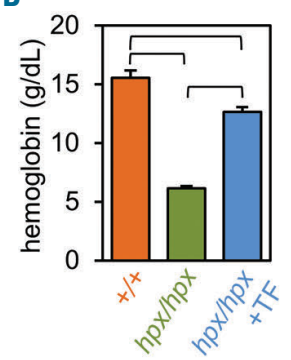

C

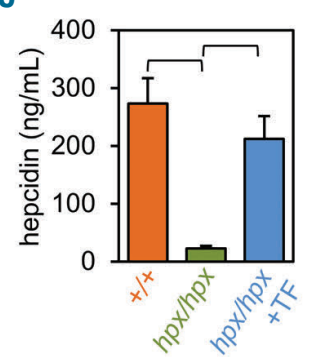

D

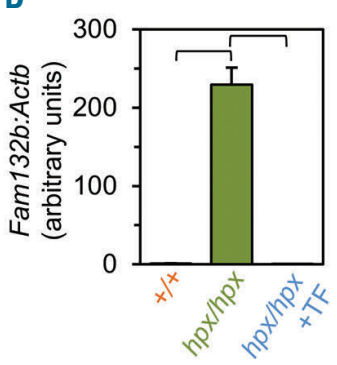

$+/+$

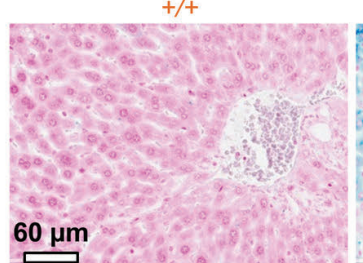

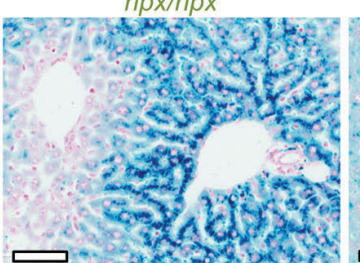
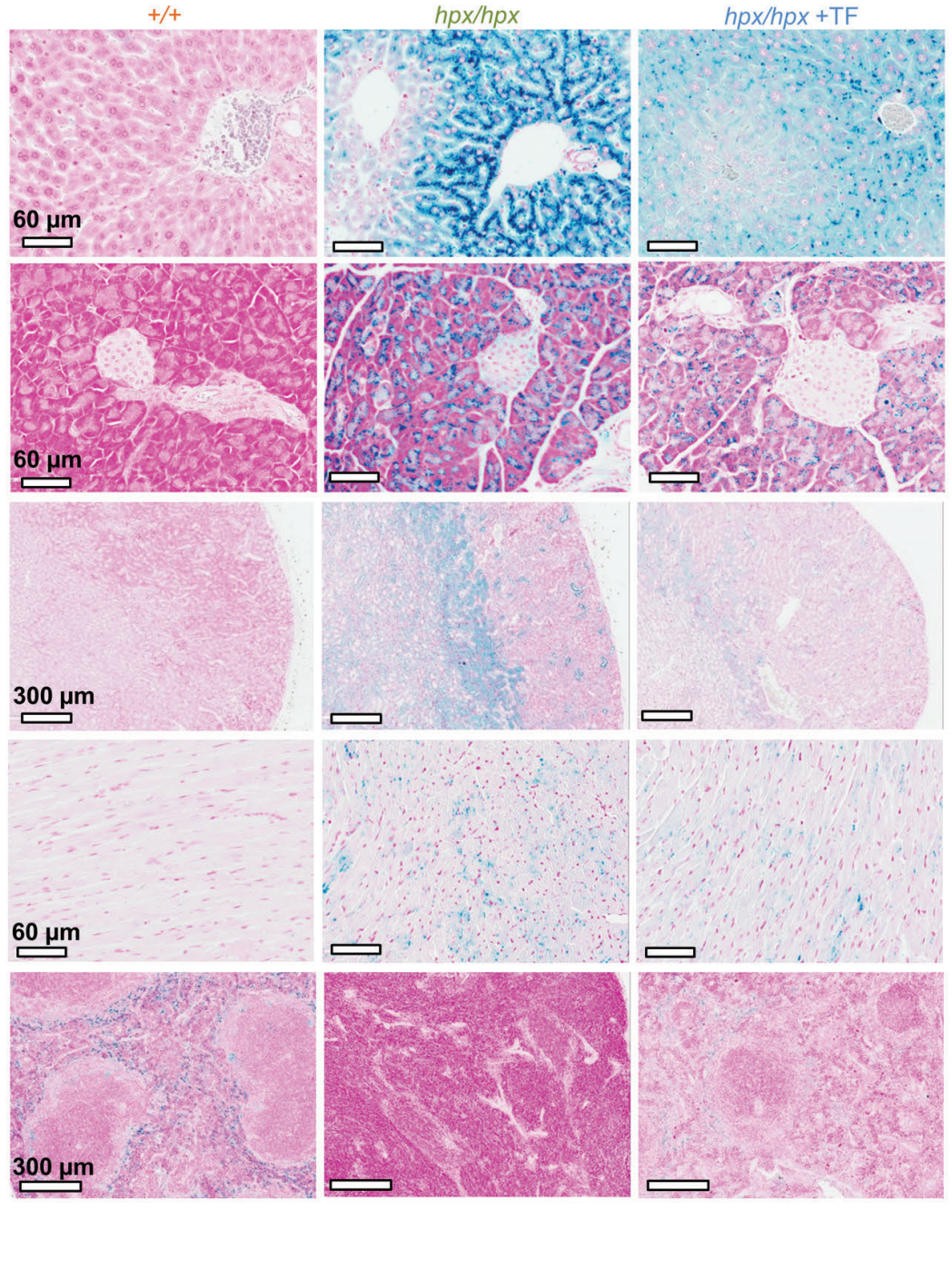

Figure 1. Short-term transferrin treatment reduces tissue iron excess in $\operatorname{Tr} f^{1 p x / h p x}$ mice. (A-D) $\operatorname{Tr} f^{+/+}\left({ }^{\prime \prime}+/+\right.$ '), untreated $\operatorname{Tr} f^{10 x / h p x}$ ('hpx/hpx'), and transferrin (TF)-treated

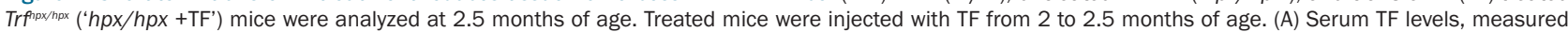
by immunoblot (top) and Coomassie-stained protein gel (bottom). (B) Hemoglobin levels, measured by complete blood count. (C) Plasma hepcidin levels, measured by ELISA. (D) Splenic RNA level ratios of Fam132b to Actb ( $\beta$-actin), measured by quantitative polymerase chain reaction and normalized to Trf ${ }^{+/+}$Ievels. (E) Organ iron (Fe) levels (left panels), measured by inductively coupled plasma absorption emission spectrometry, and tissue Fe distribution (right micrographs), assessed by tissue Fe stain. In (B-E), data are represented as the mean \pm standard error of mean. Brackets indicate statistical significance $(P<0.05)$ calculated by one-way analysis of variance with a Holm-Sidak post-hoc test. Each value represents data from five mice, with males and females grouped together. 
(see Online Supplement for details). Based upon these calculations, it is likely that changes in tissue iron levels in the first 2 weeks of transferrin treatment largely represent mobilization of iron to the bone marrow.

To explore the effect of transferrin treatment on body iron levels in $\operatorname{Tr}^{f^{i p \times} / h \mathrm{x}}$ mice beyond the first 2 weeks of treatment, we measured body iron content in 1- to 6-

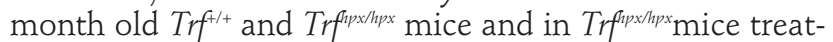
ed with transferrin from 2 to 6 months of age. The mice were euthanized in order to measure body iron content and no blood was removed prior to euthanasia. After mouse pelts had been removed, gastrointestinal tracts were isolated and cleared of contents. Pelts, cleared gas- trointestinal tracts, and carcasses were then analyzed for iron levels, which were summed to calculate body iron levels. We focused on body iron levels here as these would not be affected by redistribution between organs. Untreated $T r f^{t_{p} \times / h p x}$ mice were smaller than $\operatorname{Tr}^{\mathrm{A} /+}$ mice, and treatment increased body sizes of $\operatorname{Tr}^{f^{p x x} / h p x}$ mice (Figure $3 \mathrm{~A})$. Body iron levels (in mg iron) and concentrations (in $\mu \mathrm{g}$ iron/g body mass) were greater in untreated $\operatorname{Tr}^{A i p \times / h p \times}$ mice than in $\operatorname{Tr}^{1++}$ mice (Figure 3B,C). Treatment of Trf ${ }^{f p x / h p x}$ mice resulted in no difference in iron levels and a less than two-fold difference in iron concentrations relative to those in $\operatorname{Trf}^{1 /+}$ mice by 6 months of age (Figure 3B,C). Most untreated $\operatorname{Tr}^{A p \times / h p x}$ mice did not survive to 6 months,
A

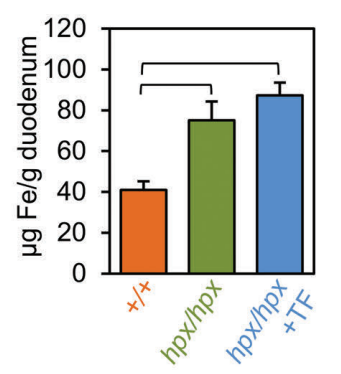

B
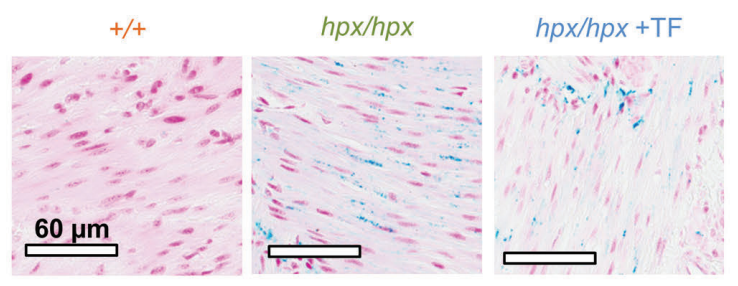

C

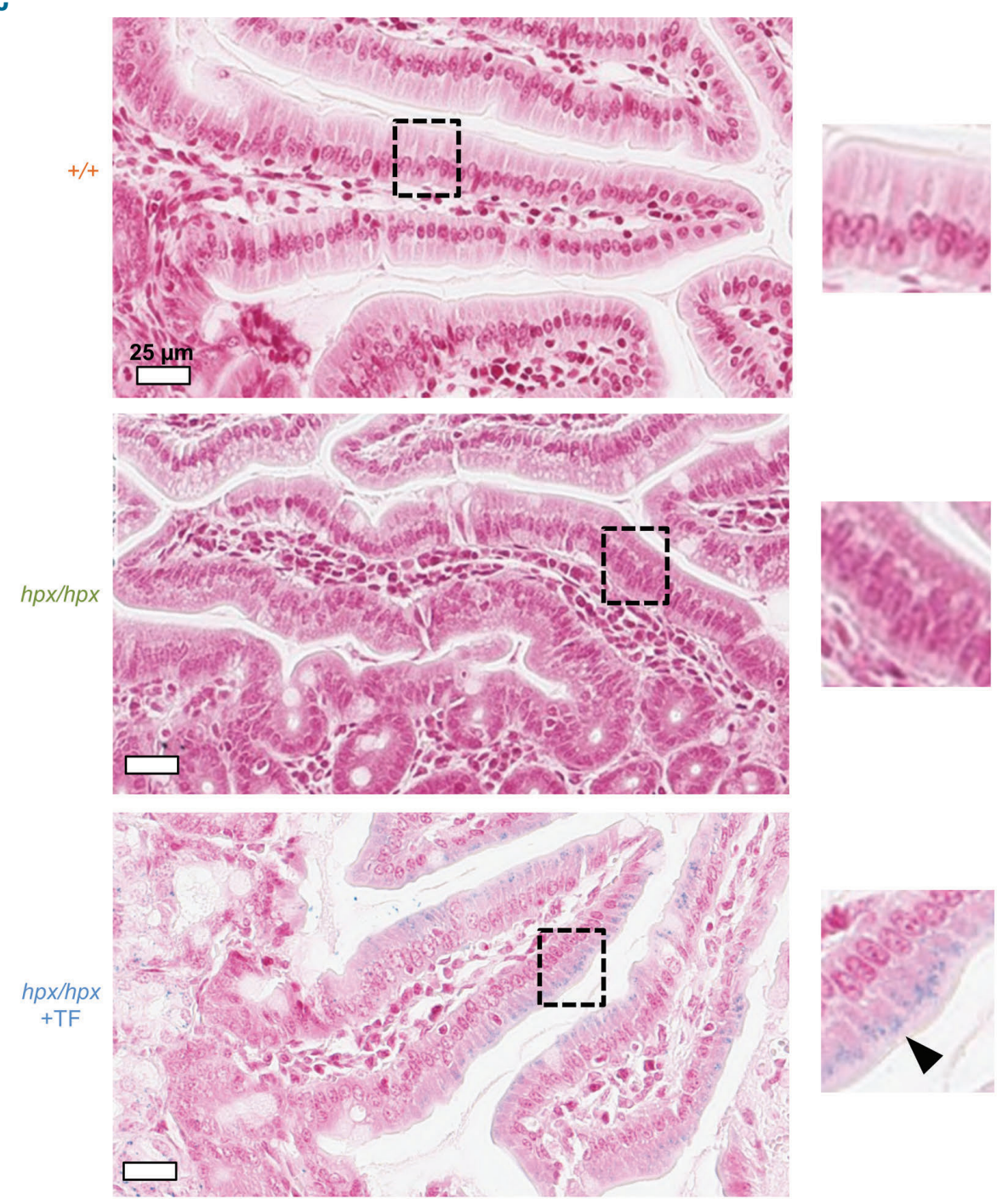

Figure 2. Trf ${ }^{n x / h p x}$ mice accumulate iron in the duodenum. (A-C) Mice from Figure 1 were analyzed for duodenal iron (Fe) levels by inductively coupled plasma absorption emission spectrometry $(\mathrm{A})$ and tissue Fe staining in duodenal smooth muscle (B) and villi (C). In (A), data are represented as the mean \pm standard error of mean. Brackets indicate statistical significance $(P<0.05)$ calculated by oneway analysis of variance with a Holm-Sidak post-hoc test. Each value represents data from five mice, with males and females grouped together. In (C), the arrowhead indicates detectable Fe staining in duodenal enterocytes. 
which may reflect chronic effects of iron excess and/or anemia. Overall, given that body iron levels would not be affected by iron redistribution between organs, we hypothesized that the long-term change in body iron levels in transferrin-treated Tr $f^{\text {pix } x h p x}$ mice reflected changes in absorption and/or excretion.

\section{$\mathrm{Trf}^{+/+}$and treated $\mathrm{Trf}^{\mathrm{fip} / h \mathrm{hx}}$ mice have similar ${ }^{59} \mathrm{Fe}$ absorption rates}

Untreated Tr $f^{\text {pix } x h p x}$ mice absorb iron excessively. ${ }^{14}$ If transferrin treatment suppresses absorption rates below excretion rates, body iron levels would decrease without any need for increased excretion rates in $\operatorname{Tr}^{f p^{p x} \times h x}$ mice. To test this hypothesis, we performed intragastric ${ }^{59} \mathrm{Fe}$ gav-

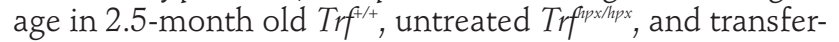
rin-treated $\operatorname{Tr}{ }^{f p x / h p x}$ mice, then analyzed ${ }^{59} \mathrm{Fe}$ levels $16 \mathrm{~h}$ later. From herein we studied males and females separately to detect sex-specific differences. Untreated Trf fipxhpx mice absorbed more gavaged ${ }^{59} \mathrm{Fe}$ than did $\mathrm{Tr}^{\mathrm{f}^{\prime /}}$ and treat-

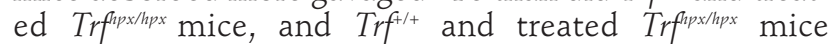
absorbed the same amount of ${ }^{59} \mathrm{Fe}$ (Figure 4A). Similar results were observed when absorption values were normalized to body mass (Figure 4B) or when mice were analyzed $1 \mathrm{~h}$ after gavage (data not shown). This indicated that reversal of iron excess in transferrin-treated Trfipxhppx mice was not due to 'hypersuppression' of iron absorption.

\section{$\mathrm{Trf}^{+/+}$and treated $\operatorname{Trf}^{f p x / h p x}$ mice have similar \\ ${ }^{59} \mathrm{Fe}$ half-lives}

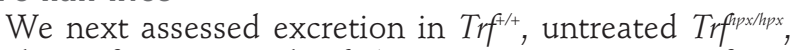
and transferrin-treated $\operatorname{Tr} f^{i p x} \times h_{p x}$ mice using ${ }^{59} \mathrm{Fe}$. Mice from the absorption studies were used, as we rationalized that gavage was the most physiological means of administering ${ }^{59} \mathrm{Fe}$. We repeatedly measured body ${ }^{59} \mathrm{Fe}$ levels in mice for 2 months from 2.5 to 4.5 months of age (Figure 4C).
We ended the excretion study at 4.5 months as untreated $T f^{i p \times h h x}$ mice do not consistently survive past this age. Body ${ }^{59} \mathrm{Fe}$ levels, plotted versus time, were fitted to exponential decay curves. Exponential decay equations were then used to calculate two factors: biological ${ }^{59} \mathrm{Fe}$ halflives, expressed in days, and percent body ${ }^{59} \mathrm{Fe}$ excreted per day, referred to here as ${ }^{659} \mathrm{Fe}$ excretion rates'. ${ }^{59} \mathrm{Fe}$ halflives and ${ }^{59} \mathrm{Fe}$ excretion rates are inversely proportional to each other. ${ }^{59} \mathrm{Fe}$ half-lives were $~ 80-120$ days in all mice except for untreated male Trfipxiphx mice, which had a halflife of $\sim 170$ days (Figure $4 \mathrm{D}) .{ }^{59} \mathrm{Fe}$ excretion rates were $\sim 0.6-0.8 \%$ in all mice except for male $T$ Tr $^{\text {ip } x / h p x}$ mice, which had an excretion rate of $\sim 0.45 \%$ (Figure $4 \mathrm{E}$ ). Notably, ${ }^{59} \mathrm{Fe}$ half-lives and excretion rates did not differ between $\mathrm{Trf}^{\mathrm{f}^{\prime}}$ and untreated $\operatorname{Tr}^{t_{1} \times x / h p x}$ mice.

\section{Trf mice excrete iron largely via the gastrointestinal tract}

During the 2-month excretion study, mice were placed repeatedly in metabolic cages for overnight collections of feces and urine. Fecal and urinary ${ }^{59} \mathrm{Fe}$ levels were expressed as a percent of body ${ }^{59} \mathrm{Fe}$ levels at the time of collection, then averaged for each mouse group. Most ${ }^{59} \mathrm{Fe}$ was excreted in feces (Figure 4F). Body ${ }^{99} \mathrm{Fe}$ losses could be accounted for by fecal and urinary ${ }^{59} \mathrm{Fe}$ losses in all mice except transferrin-treated $\operatorname{Tr}^{f i p x y}$ hpx females (Figure 4G). Overall, these data indicate that Trf mice excreted iron largely via the gastrointestinal tract.

\section{${ }^{59} \mathrm{Fe}$-based analyses predict relative abundance of urinary iron and fecal ferritin in Trf mice}

In some of the earliest radioisotope-based studies of iron excretion in mice, Finch and colleagues multiplied body ${ }^{59} \mathrm{Fe}$ excretion rates by body iron levels to estimate the amount of iron excreted per day. ${ }^{17,18}$ We employed this approach here to further explore iron excretion in Trf
A
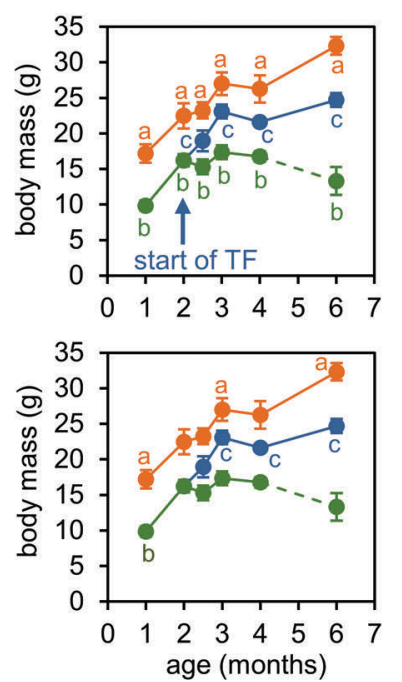

B
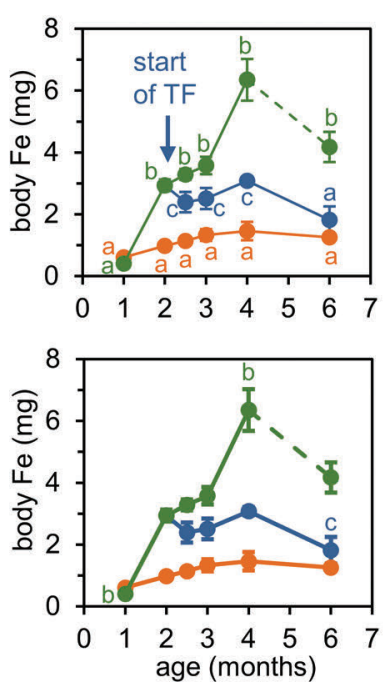

C
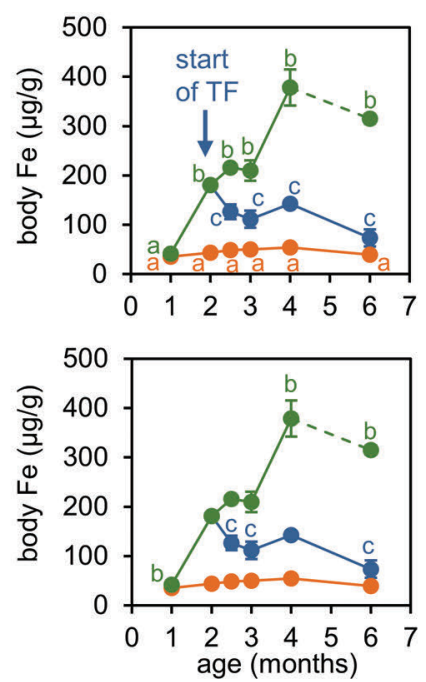

For given age, different letters denote $\mathrm{P}<0.05$

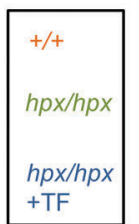

For given group, letter indicates $\mathrm{P}<0.05$ vs. 2 months

Figure 3. Long-term transferrin treatment corrects body iron excess in Trfipx/hpx mice. (A-C) Body masses (A) and iron (Fe) levels (B) and concentrations (C), measured in $\operatorname{Trf}^{+/+}$mice ('+/+', orange) and untreated $\operatorname{Tr} f^{h p x / h p x}$ mice ('hpx/hpx', green) from 1 to 6 months of age and in Trf ${ }^{f p x / h p x}$ mice treated with transferrin (TF) from 2 to 6 months of age ('hpx/hpx +TF', blue). Top and bottom graphs differ only by markers of significance $(P<0.05)$ assessed by two-way analysis of variance with a HolmSidak post-hoc test. In top panels, for a given age, different letters indicate values that differ significantly. In bottom panels, for a given group, the letter indicates that a value differs significantly from the 2-month old value. In all panels, dashed lines indicate that only two untreated Trfipx/hpx mice survived to 6 months. Data are represented as mean \pm standard error of mean: each value represents data from five mice, with males and females grouped together. 
mice. We performed this for 2.5- and 4.5-month-old mice, the respective ages at the beginning and end of the excretion study.

We first established body iron levels and concentrations in 2.5- and 4.5-month-old mice (Figure 5A,B). For 2.5month-old mice, we measured body iron levels and concentrations in five male and five female mice for each experimental group using the same approach employed for Figure 3. For 4.5-month old mice, we harvested all tissues/compartments from mice at the end of the excretion study and measured iron levels and concentrations (Table 1). Iron levels for 2.5 - and 4.5-month old mice were consistent with iron levels shown in Figure 3 where sexes were pooled (Online Supplementary Figure S1). With body iron levels established in 2.5- and 4.5-month old mice, we next multiplied ${ }^{59} \mathrm{Fe}$ excretion rates (Figure $4 \mathrm{E}$ ) by body iron levels (Figure 5A) or body iron concentrations (Figure $5 \mathrm{~B})$ to estimate iron excretion rates with and without normalization to body mass (Figure 5C,D). At 2.5 months, iron excretion rates were predicted to be increased in all $\operatorname{Tr} f^{i n x h p x}$ mice except untreated males when not normalized to body size and in all $\operatorname{Tr}^{f^{1 p x} / h p x}$ mice when normalized to body size. At 4.5 months, excretion rates were predicted to be increased in all $\operatorname{Tr}^{f_{i p x} x h x}$ mice irrespective of normalization to body size.

The above approach involves several assumptions. The first is that ${ }^{59} \mathrm{Fe}$ is fully equilibrated within each mouse. To explore this, we examined the relative distribution of ${ }^{59} \mathrm{Fe}$
A

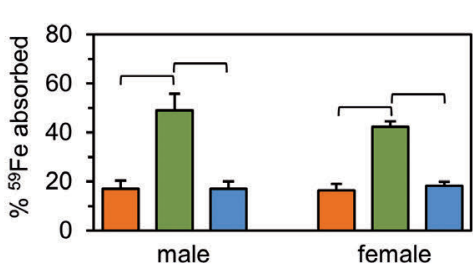

C
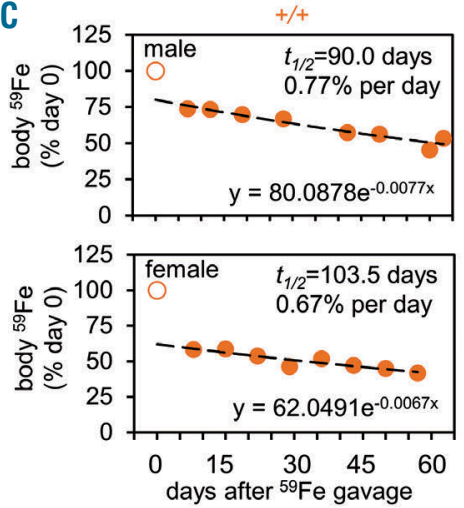

D

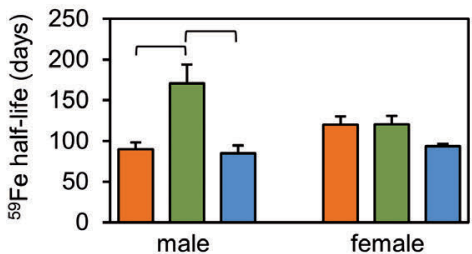

$\mathrm{E}$

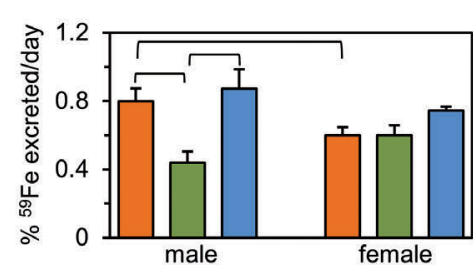

$\mathrm{F}$

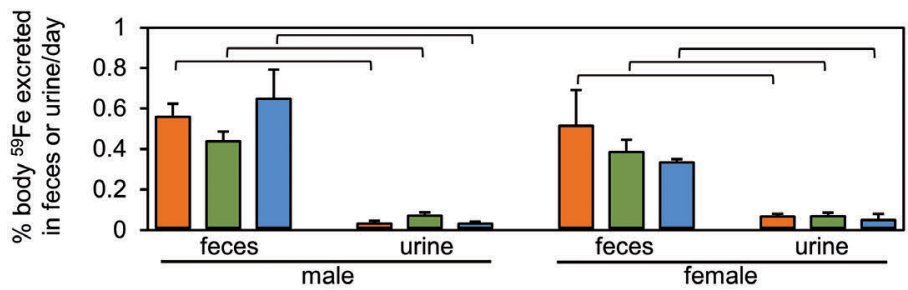

G

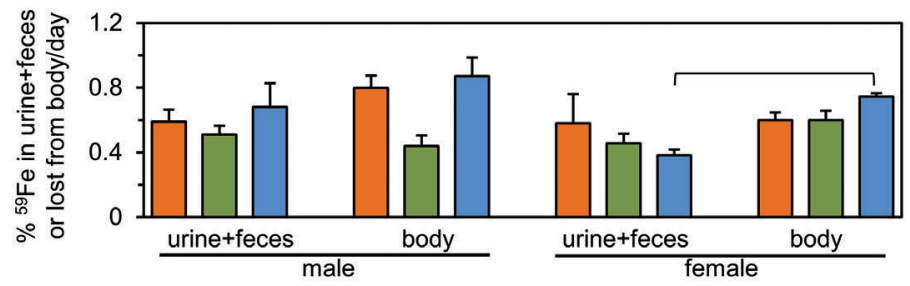

B

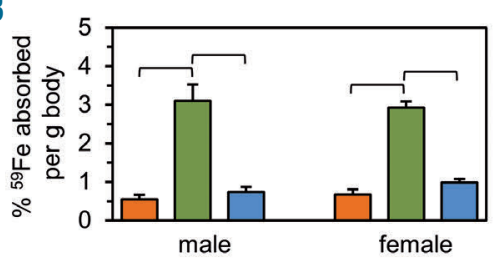

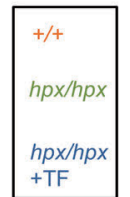

Figure 4. $T r f^{+/+}$and treated $T r f^{1 p x / h p x}$ mice have similar ${ }^{59} \mathrm{Fe}$ absorption rates and half-lives and excrete iron largely via the gastrointestinal tract. (A) Percent ${ }^{59} \mathrm{Fe}$ absorbed, measured after ${ }^{59} \mathrm{Fe}$ gavage of male and female 2.5-month old $\mathrm{Trf}^{+/+}$ mice ('+/+', orange), untreated $\operatorname{Tr} f^{h p x / h p x}$ mice (' $h p x / h p x$ ', green), and $\operatorname{Tr} f^{f^{1} x / h p x}$ mice treated with transferrin (TF) (' $h p x / h p x+T F$ ', blue) from 2 to 2.5 months of age. Percent ${ }^{59} \mathrm{Fe}$ absorbed was calculated as the sum of body and urinary ${ }^{59} \mathrm{Fe}$ levels expressed as a percent of body, urine, and feces ${ }^{59} \mathrm{Fe}$ levels. (B) Values from (A) normalized to body size. (C) Representative plots of body ${ }^{59} \mathrm{Fe}$ levels from 2.5 to 4.5 months of age in $\mathrm{Trf}^{+/+}$mice, untreated $\operatorname{Tr} f^{1 p x / h p x}$ mice, and $\operatorname{Tr} f^{n p x / h p}$ mice treated with TF from 2 months of age ("hpx/hpx +TF", blue). 'Day 0 ' indicates the day after ${ }^{59} \mathrm{Fe}$ gavage. Unfilled circles at day 0 indicate that these points were excluded from lines of best fit. Exponential decay equations, ${ }^{59} \mathrm{Fe}$ half-lives $\left(t_{1 / 2}\right)$, and percent ${ }^{59} \mathrm{Fe}$ excreted per day are included in each graph. (D) ${ }^{59} \mathrm{Fe}$ half-lives, calculated by exponential decay equations from (C). (E) Percent ${ }^{59} \mathrm{Fe}$ excreted per day, or ${ }^{59} \mathrm{Fe}$ excretion rates', calculated by exponential decay equations from (C). (F) Percent body ${ }^{59} \mathrm{Fe}$ excreted per day via feces or urine in mice from 2.5 to 4.5 months of age. Feces and urine were collected by housing each mouse overnight in metabolic cages at least three times during the excretion study. (G) Sums of fecal and urinary ${ }^{59} \mathrm{Fe}$ values from (F) ("urine+feces") compared to body ${ }^{59} \mathrm{Fe}$ excretion rates from (E) ("body loss"). In all panels except (C), data are represented as mean \pm standard error of mean with each value shown representing data from at least five mice and brackets indicating $P<0.05$. Statistical significance was calculated by one-way analysis of variance with a Holm Sidak post-hoc test in (A, B, D, E) and by a two-tailed $t$-test in $(F, G)$. 
versus iron within each experimental group harvested at the end of the excretion study at 4.5 months of age. ${ }^{59} \mathrm{Fe}$ and iron levels correlated significantly in all groups (Online Supplementary Figure S2A). The second assumption is that ${ }^{59} \mathrm{Fe}$ equilibrates similarly in all mice. To explore this, we examined the relative distribution of ${ }^{59} \mathrm{Fe}$ between $\operatorname{Tr}^{\prime /+}$ and untreated or treated $\operatorname{Tr}^{f i p \times / h p x}$ mice. Relative distributions correlated more strongly between

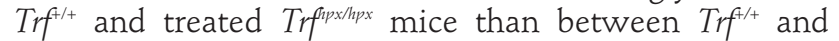
untreated $\operatorname{Tr}^{f i p \times h p x}$ mice (Online Supplementary Figure S2B). This was not unexpected - treated mutant mice were administered ${ }^{59} \mathrm{Fe}$ after 2 weeks of transferrin treatment during which time hemoglobin and hepcidin levels increased significantly (Figure 1B,C).

To explicitly test ${ }^{59} \mathrm{Fe}$-based estimates of excretion, we next used ${ }^{59} \mathrm{Fe}$ levels measured during the excretion study to predict urinary iron levels, then measured and com- pared actual excreted urinary iron levels to predicted levels. We first focused on urinary iron levels given that they solely reflect excretion. To estimate urinary iron levels, values of percent body ${ }^{59} \mathrm{Fe}$ excreted in urine per day (Figure 4F) were multiplied by body iron levels (Figure $5 \mathrm{~A})$. Urinary iron levels were estimated to be increased in

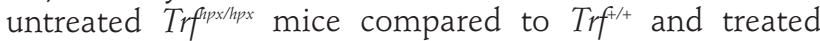
$\operatorname{Tr}^{t f^{p \times} \times h p x}$ mice at 2.5 and 4.5 months of age (Figure 5E). Measurement of urinary iron levels agreed with the prediction that untreated mutant mice excreted more iron via urine than wild-type or treated mutant mice (Figure 5E and Online Supplementary Figure S3). Measured urinary iron levels also agreed with ${ }^{59} \mathrm{Fe}$-based predictions for all treated $\operatorname{Tr}^{f_{i p x} \times / h x}$ mice. However, urinary iron levels were underestimated by ${ }^{59} \mathrm{Fe}$-based predictions by $5-10 \mu \mathrm{g}$ iron per day in all untreated mutant mice and by $2 \mu \mathrm{g}$ iron per day in female untreated mutant mice.
A

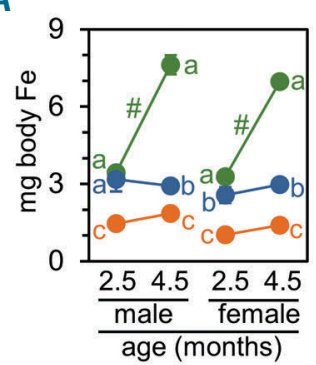

B

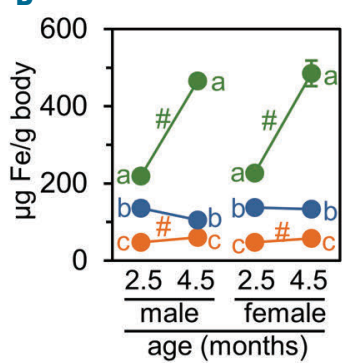

C

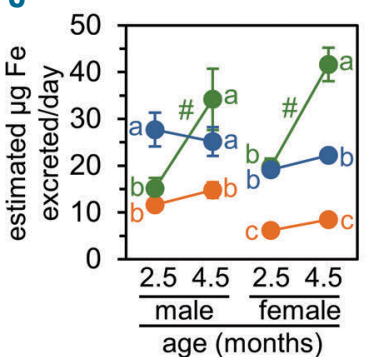

D

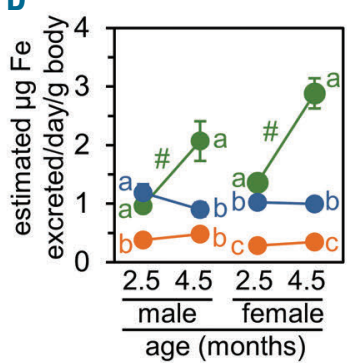

E
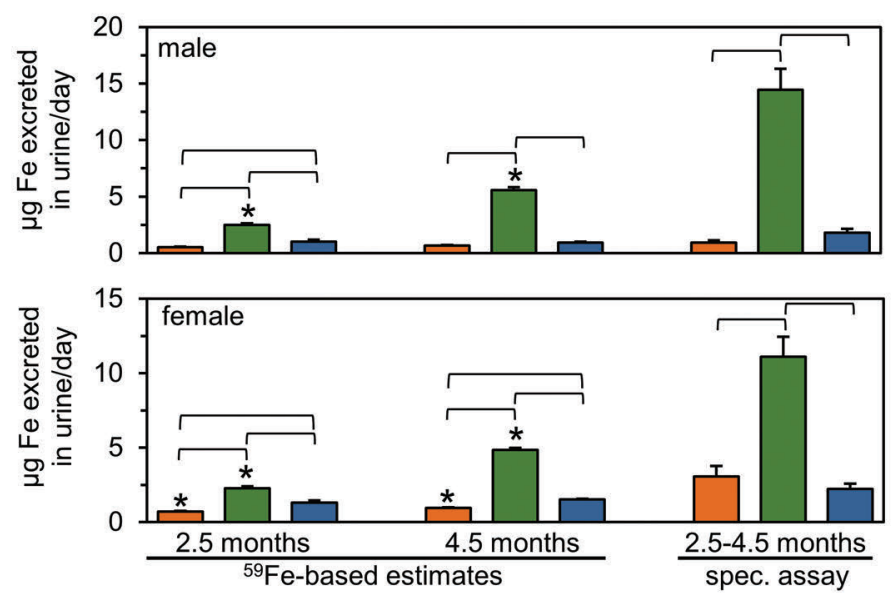

$\mathbf{F}$
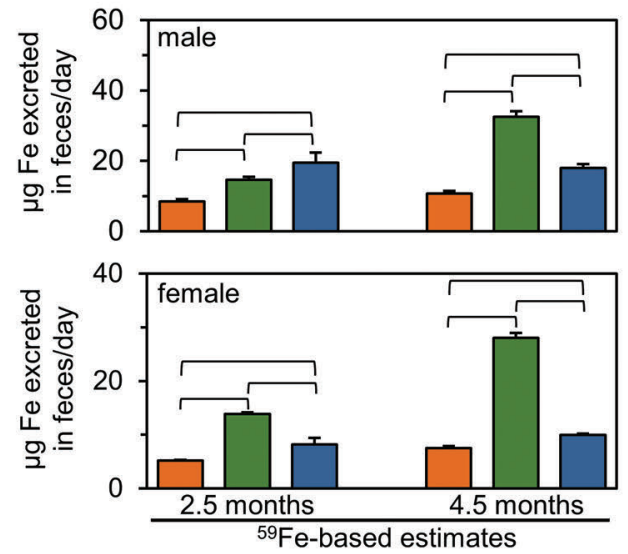

G
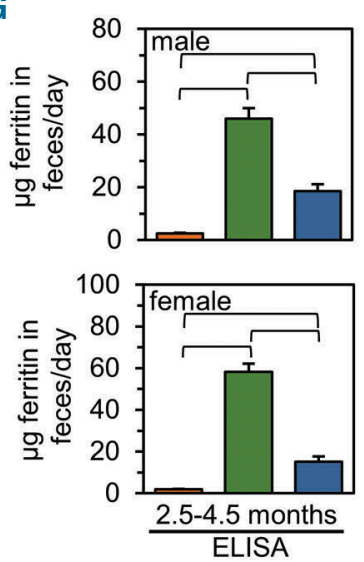

Figure 5. ${ }^{59} \mathrm{Fe}$-based analyses predict relative abundance of urinary iron and fecal ferritin in Trf mice. (A, B) Body iron (Fe) levels (A) and concentrations (B) in $\mathrm{Tr}^{+/+}$mice ('+/+', orange), untreated $T r f^{h p x / h p x}$ mice (' $h p x / h p x$ ', green), and Trfipx/hpx mice treated with transferrin (TF) (' $h p x / h p x+T F$ ', blue) harvested at 2.5 months or 4.5 months of age at the end of the excretion study shown in Figure 4. (C) $\mu \mathrm{g}$ Fe excreted per day, calculated by multiplying values in Figure $4 \mathrm{E}$ by values in (A). (D) $\mu \mathrm{g}$ Fe excreted per day normalized to body size, calculated by multiplying values in Figure 4E by values in (B). (E) $\mu \mathrm{g}$ Fe excreted per day in urine. ${ }^{59} \mathrm{Fe}$-based estimates were calculated by multiplying urinary values in Figure $4 \mathrm{~F}$ by values in (A). Spectrophotometric measurements ('spec assay') were calculated by acid digest and BPS-based assay as described in the Online Supplementary Methods. (F) $\mu \mathrm{g}$ Fe excreted per day in feces, estimated by multiplying fecal values in Figure 4F by values in $(A)$. (G) $\mu g$ ferritin excreted per day in feces measured by enzyme-linked immunosorbent assay. In all panels, data are represented as mean \pm standard error of mean; each value shown represents data from at least five mice. In (A-D), at a given age, different letters indicate $P<0.05$ between values, calculated by one-way analysis of variance with a HolmSidak post-hoc test; '\#' indicates $P<0.05$ between values from 2.5- and 4.5-month old mice, calculated by a two-tailed $t$-test. In (E$\mathrm{G})$, brackets indicate $P<0.05$, calculated by one-way analysis of variance with a HolmSidak post-hoc test. In (E), asterisks indicate $P<0.05$ between ${ }^{59} \mathrm{Fe}$-based and spectrophotometry-based values, calculated by a twotailed $t$-test. 
We next used ${ }^{59} \mathrm{Fe}$ measurements to investigate fecal iron excretion. To estimate excreted iron levels in feces, values of percent body ${ }^{59} \mathrm{Fe}$ excreted in feces per day (Figure 4F) were multiplied by body iron levels (Figure
5A). Fecally excreted iron levels were estimated to be increased in all $\operatorname{Tr}^{i p \times x / h p x}$ mice relative to $\operatorname{Tr}^{4 /+}$ mice and increased in untreated $\operatorname{Tr}^{f_{p \times} \times h p x}$ mice relative to treated $\operatorname{Tr} f^{\operatorname{tip} x h p x}$ mice for all mice except 2.5-month old male mice

Table 1. Long-term transferrin treatment reduces or normalizes organ iron content in $\operatorname{Trffpx}^{\text {hpx }}$ mice.

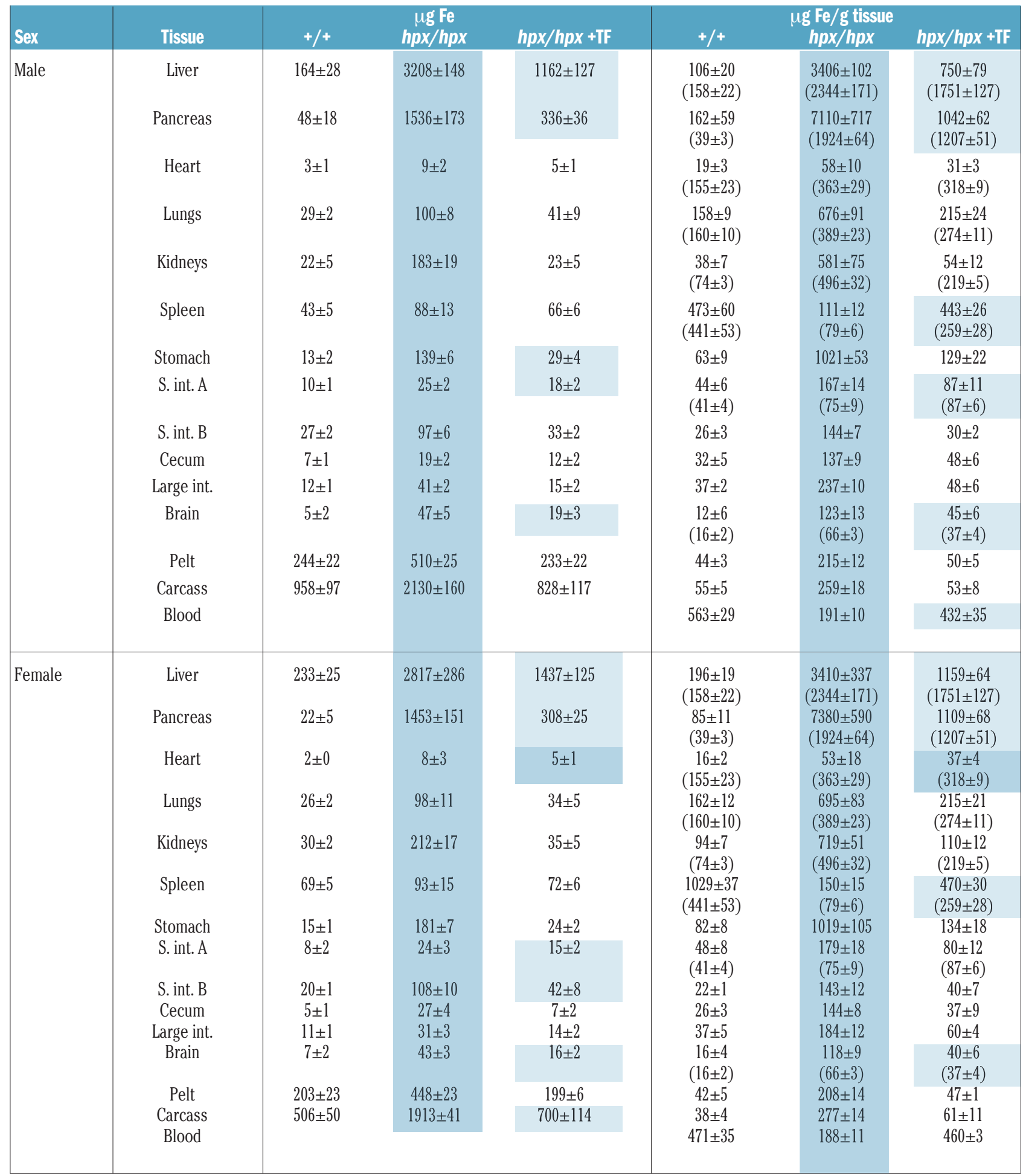

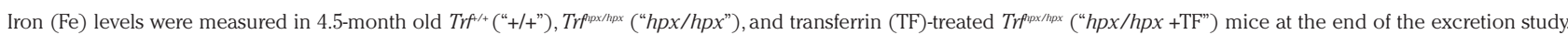
TF-treated $\operatorname{Tr}^{f i p x / h p x}$ mice were treated with TF from 2 to 4.5 months of age. Digestive organs including intestines ('int'.) were cleared of luminal contents before analysis. 'S. int. A' refers to the first $4 \mathrm{~cm}$ of the small intestine; 'S. int. B' refers to the remaining small intestine. Cells with different shading differ significantly $(P<0.05)$ for a specific organ and sex, as calculated by one-way analysis of variance with the Holm-Sidak post-hoc test. Each value represents the mean \pm standard error of mean of the data from at least five mice. For reference, tissue Fe levels from 2.5-month old mice shown in Figures 1 and 2 are included in parentheses; note that parenthetical tissue Fe levels represent data from five mice with males and females pooled. 
A

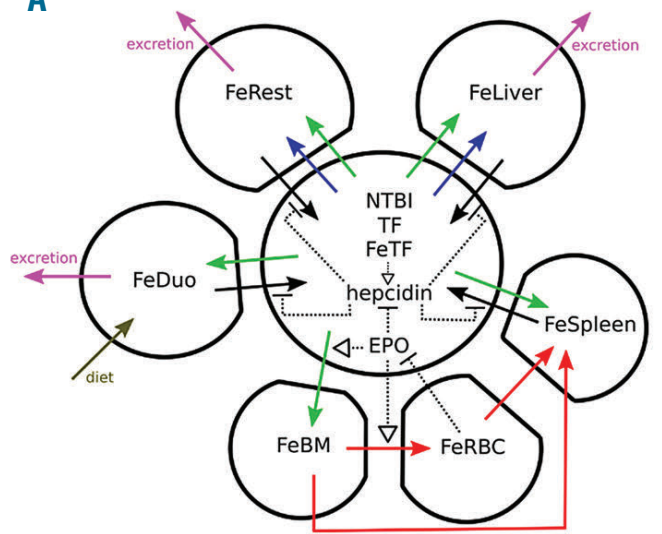

B

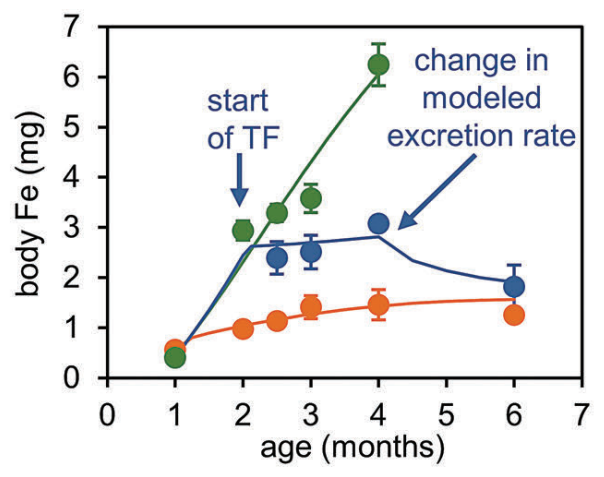

Experimental

- +/+

- $h p x / h p x$

- $h p x / h p x+T F$

Model

+ + +

hpx/hpx

- $h p x / h p x+\mathrm{TF}$

Figure 6. Mathematical modeling predicts increased excretion rates in treated $T r f^{h p x / h x}$ mice. (A) The iron (Fe) homeostasis scheme used for mathematical modeling of body Fe levels from Figure 3B. Closed polygons represent liver, spleen, red blood cells (RBC), bone marrow (BM), duodenum (Duo), or 'rest of body' (Rest), the last comprising stomach, intestines except the duodenum, integument, muscles, heart, fat, lungs, kidneys, brain, and reproductive organs. The circle represents plasma. Dietary Fe is absorbed into the duodenum (solid dark green arrow) and exported to plasma by ferroportin (solid black arrow). Plasma Fe, in states of Fe homeostasis, exists as Fe-loaded transferrin (FeTF) which is imported into all compartments (solid light green arrows) except RBC or, in states of Fe excess, as non-transferrinbound iron (NTBI) which is imported into the liver and rest of the body (solid blue arrows). Bone marrow Fe is incorporated into RBC and recycled in the spleen (solid red arrows); direct Fe transfer from the bone marrow to the spleen represents recycling of immature erythroid cells in the spleen (solid red arrows). Fe can be exported from compartments by ferroportin (solid black arrows). FeTF stimulates hepcidin expression (dashed black arrow), which inhibits ferroportin-dependent Fe export from compartments (dashed blunt-ended lines). Erythropoietin (EPO) stimulates FeTF import into the bone marrow, transfer of Fe from the bone marrow to RBC, and suppression of hepcidin activity. EPO is suppressed by increased RBC Fe levels. Fe can be excreted from the liver, duodenum, and the rest of the body (solid magenta lines). (B) Results of mathematical modeling. Experimental values from Figure 3B are shown as circles. Modeled values are shown as lines.

(Figure 5F). Measurement of total fecal iron levels indicated no significant difference between any experimental group (Online Supplementary Figure S4). This was expected given that total fecal iron levels are affected by multiple factors beyond excretion, including dietary iron levels and iron absorption. Analysis of ${ }^{59} \mathrm{Fe}$-labeled compounds in feces was not possible $-{ }^{59} \mathrm{Fe}$ levels were low at the time of collecting the feces and decayed significantly once all mice had been processed in the excretion study. As fecal ferritin levels have been reported to reflect body iron levels ${ }^{19}$, we next measured fecal ferritin levels by ELISA. Similar to our estimates of fecally excreted iron (Figure $5 F)$, fecal ferritin levels were increased in all Tr $f^{f p x / h p x}$ mice relative to $\operatorname{Trf}^{\mathrm{f} / \mathrm{s}}$ mice and increased in untreated $\operatorname{Tr}^{f^{i p \times} \times h p x}$ mice relative to treated $\operatorname{Tr}^{f^{1 p x} x / h x}$ mice (Figure 5G, Online Supplementary Figure S5). We next attempted to assess ferritin iron levels in fecal samples. Using mouse liver lysates, we established that the same iron stain used for histology could be used to detect a species very abundant in $\operatorname{Tr}^{i p \times / h p x}$ mouse liver that comigrated with ferritin heavy and light chain under native PAGE conditions (Online Supplementary Figure S6). However, native PAGE of fecal lysates failed to reveal stainable iron (data not shown).

\section{Mathematical modeling predicts increased excretion rates in treated $\operatorname{Tr} f^{h p x / h p x}$ mice}

We also analyzed body iron levels from Figure 3B using our mathematical model of iron homeostasis, summarized in Figure 6A. ${ }^{20}$ The goal here was to explore the decrease in body iron content in transferrin-treated $\operatorname{Tr}^{i p x / h p x}$ mice from 4 to 6 months (Figure 3B,C) - our excretion study was halted at 4.5 months as not all untreated $\operatorname{Tr}^{4 p x / h p x}$ mice survived to 6 months. Using the model, we could fit body iron levels from $T r f^{1 /+}$ and untreated $T r f^{n p \times / h p x}$ mice with good agreement between experimental and modeled values (Figure 6B). However, we were unable to reproduce iron levels in 6-month old untreated $\operatorname{Tr}^{4 i p \times / h p x}$ mice. As most untreated $\operatorname{Tr} f^{a p x / h p x}$ mice die before 6 months, iron loss at this age may not reflect physiological excretion but rather cell death secondary to severe iron excess or other long-term adverse effects of transferrin deficiency. When we simulated body iron levels in transferrin-treated $\operatorname{Tr} f^{i p \times / h p x}$ mice, we could reproduce body iron levels up to 4 months but were initially unable to reproduce the decrease in body iron levels from 4 to 6 months. We considered that the decrease in iron levels from 4 to 6 months in transferrin-treated $\operatorname{Tr}^{i p \times / h p x}$ mice required an increase in excretion from one or more compartments or a decrease in absorption starting at 4 months. The smallest change in absorption or excretion that fitted the data was a four-fold increase in excretion from the duodenum and 'rest of body'. Given that 'rest of body' in our model comprised other gastrointestinal regions including jejunum, ileum, and large intestine, this supports our ${ }^{59} \mathrm{Fe}-$ based studies indicating that the gastrointestinal tract is the main route of excretion.

\section{Discussion}

In this study, we exploited our initial observation that transferrin treatment decreases the concentrations of iron in the organs of $\operatorname{Tr}^{a p x / h p x}$ mice to explore the basis of iron excretion. For this objective, the $\operatorname{Tr} f^{t p x / h p x}$ model has some key advantages over other mouse models of common human diseases of iron excess such as hereditary hemochromatosis and $\beta$-thalassemia. First, Trt ${ }^{f_{p x} / h p x}$ mice develop more severe iron excess than most other models. We anticipated that the severity of iron excess would significantly increase iron levels in potential routes of excretion such as feces and urine. Second, the primary defect in $\operatorname{Tr}^{f^{i p x} / h p x}$ mice can be rapidly corrected pharmacological- 
ly. In contrast, the primary defect in $\beta$-thalassemia mouse models - $\beta$-globin mutations - cannot. Red cell transfusions can reverse the anemia in this disease but also introduce a large burden of exogenous iron.

As mentioned above, organ iron concentrations decreased in transferrin-treated Trtipx/hpx mice. A similar phenomenon has been described in mouse models of hereditary hemochromatosis and $\beta$-thalassemia. Hepcidin deficiency is a key characteristic of both diseases. Administration of pharmacological agents that induce hepcidin expression or mimic hepcidin activity decreased iron levels in mouse models of these diseases. ${ }^{21-}$

${ }^{25}$ Whether correction of hepcidin deficiency simply prevented worsening of organ iron excess or led to mobilization of iron from these organs and excretion from the body remains to be determined. We propose that the decreased organ iron levels in these models reflects a combination of normalized iron absorption and increased excretion rates.

The increased excretion rates we estimated for Trf mice are similar to those previously reported. In two of the earliest studies on iron excretion in mice, injected ${ }^{55} \mathrm{Fe}$ cleared from the body of Swiss mice with a half-life of 140 days, which is equivalent to a loss of $0.5 \%$ body ${ }^{55} \mathrm{Fe}$ per day. ${ }^{17,18}$ We observed that ${ }^{59} \mathrm{Fe}$ cleared from all Trf mice except untreated male $\operatorname{Tr} f^{\text {ipx } / \text { ppx }}$ mice with a half-life of 80-120 days and a loss of $0.6-0.8 \%$ body ${ }^{59} \mathrm{Fe}$ per day (Figure $4 \mathrm{D}, \mathrm{E})$. In the older studies, iron-sufficient Swiss mice excreted $11.5 \mu \mathrm{g}$ iron/day, while mice with increased body iron secondary to dietary or intravenous iron loading excreted 14-57 $\mu \mathrm{g}$ iron/day. These values were similar to those we predicted for Trf mice based on our ${ }^{59} \mathrm{Fe}$ studies (Figure 5C).

We also used rates of body ${ }^{59} \mathrm{Fe}$ loss in urine and feces to estimate the rate at which iron was excreted via urine and feces. Measured urinary iron levels agreed with our ${ }^{59} \mathrm{Fe}-$ based estimates of urinary iron levels except for untreated mutant mice, in which actual iron levels were much higher than predicted. The reason for this underestimation is not clear, although it may reflect the fact that perturbations in iron homeostasis in untreated $\operatorname{Tr} f^{\text {inx } x h p x}$ mice are quite severe compared to those in $\operatorname{Tr}^{\mathrm{f} /}$ and treated $\operatorname{Tr}^{f_{p y x} \times h_{p x}}$ mice. We also estimated the levels of fecally excreted iron in all mouse groups. While total fecal iron levels were not informative, the relative abundance of fecal ferritin was matched by the relative abundance of fecally excreted iron. Whether fecal ferritin solely represents a marker of iron excess in Trf mice or plays a mechanistic role in iron excretion remains to be determined. The source of fecal ferritin is also not known at this time. Possible sources include sloughed epithelial cells and biliary excretion.

We propose that our study can be used as an initial step in a reconsideration of the physiological basis of iron excretion and the significance of its role in iron homeostasis. While humans and rodents may differ in their rates and routes of iron excretion, the possibility that iron excretion affects body iron levels has implications for treatment of human disease. Notably, a seminal work by Green et al. in 1968 indicated that adult men of Bantu origin, a population with increased iron stores, have increased daily iron losses. ${ }^{26}$ Development of hepcidin mimetics or agonists is an active area of research and may lead to novel treatments for hereditary hemochromatosis, $\beta$-thalassemia, and other diseases of iron excess. ${ }^{27}$ If body iron levels are regulated largely by absorption, treatment of patients with hepcidin agonists or mimetics will prevent worsening of iron excess but will not reverse it additional treatment modalities such as chelation will be required to clear excess iron from the body. If body iron levels do influence iron excretion, treatment of patients with hepcidin agonists should result in decreased body iron burden - with rates of iron absorption normalized, excess iron will clear from the body through physiological mechanisms.

The means by which iron is excreted from the body have not yet been established. Iron excretion is currently attributed to multiple processes including exfoliation of dead skin, blood loss, and turnover of intestinal epithelium (Figure 7). Our data indicating that iron is excreted largely via the gastrointestinal tract suggest that skin exfoliation does not play a prominent role. The possibility that increased blood loss contributes prominently to excretion in $\operatorname{Tr} f^{i p \times / h p x}$ mice is also unlikely given that ${ }^{59} \mathrm{Fe}$ half-lives did not decrease in $\operatorname{Tr}^{i p \times / h p x}$ mice relative to those in $\mathrm{Trf}^{\mathrm{f}+\mathrm{t}}$ mice (Figure 4D). The possibility that turnover of intestinal epithelium is a major route of iron excretion is stronger. It is supported by the fact that intestinal epithelium in mammals turns over in less than 1 week. ${ }^{28-30}$ $\operatorname{Tr}^{f i p \times h p x}$ mice do load excess iron into gastrointestinal organs (Table 1) but histological iron staining indicates that a considerable fraction of this iron in younger mutant mice resides in smooth muscle, not enterocytes (Figure 2). Pountney et al. previously demonstrated that non-heme iron levels are similar in enterocytes isolated from $\mathrm{Tr}^{\mathrm{ft+}}$ mice and treated $\operatorname{Tr}^{f^{h p x} \times / h x}$ mice. ${ }^{31}$ Based on this, we suggest that the increased duodenal iron levels we measured in $\operatorname{Tr}^{i p \times x / h p x}$ mice largely reflect smooth muscle iron loading (Figure 2). The observation by Pountney et al. that transferrin can be internalized by enterocytes isolated from $\operatorname{Tr} f^{i p \times / h p x}$ mice may also explain stainable iron observed in enterocytes of treated but not untreated $\operatorname{Tr} f^{f_{p x} / h p x}$ mice - it may represent uptake of diferric transferrin across the basolateral membrane of enterocytes. Overall, a careful investigation of the potential role of epithelial turnover to iron excretion would require a quantitative assessment of multiple factors: enterocyte iron levels, the biochemical form of enterocyte iron, and the rate of epithelial turnover in gastrointestinal organs in multiple models of iron excess and deficiency.

Another potential contributor to gastrointestinal iron excretion is hepatobiliary excretion. This process is largely ignored by the current view of mammalian iron biology. The reason for this is not apparent. One study in rats excluded bile as a route of excretion, but this was based on the observation that bile duct ligation did not impair the decrease in body iron levels in rats switched from an iron-rich to an iron-deficient diet. ${ }^{32}$ The use of bile duct ligation is a concern given that this is an established method for inducing liver cirrhosis. ${ }^{33}$ Multiple studies, most of which were performed in rats, have shown that iron is readily detectable in bile and that biliary iron levels decrease in conditions of iron deficiency and increase in conditions of iron excess. ${ }^{34-52}$ Several of these studies involved the use of chelators - our statement that iron is readily detectable in bile refers to the measurement of biliary iron in control animals not exposed to chelators. Overall, a full investigation of the contribution of biliary excretion to systemic iron excretion would require measurement of multiple parameters. While our preliminary analysis indicates that biliary iron levels are increased in 


\section{ABSORPTION}

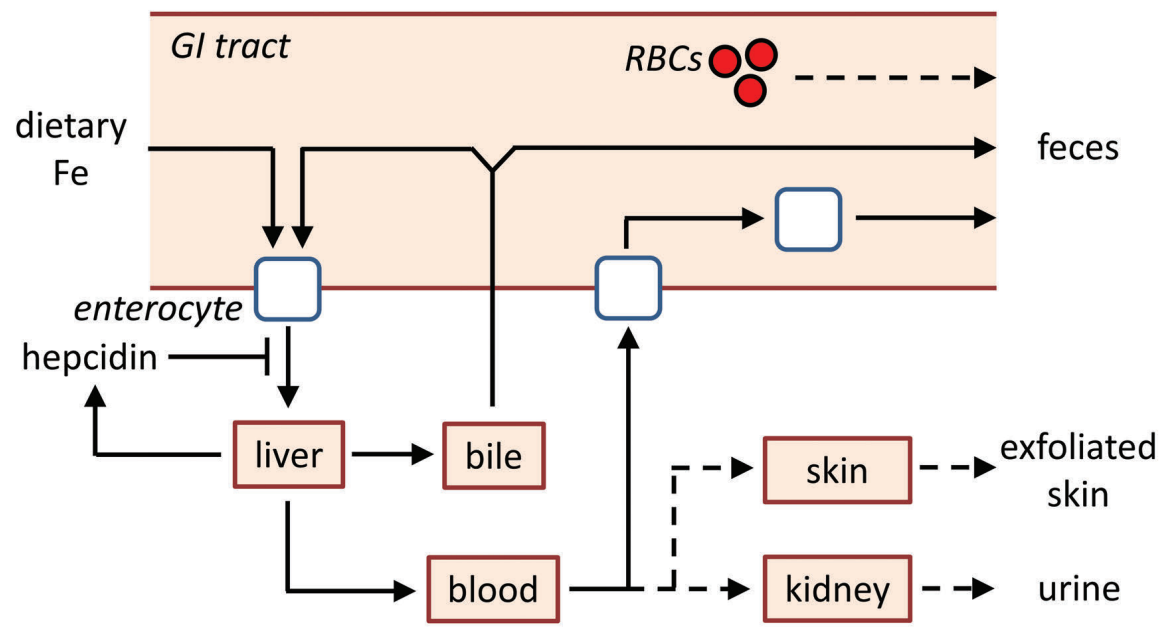

Figure 7. Model of iron absorption and excretion. Dietary non-heme iron (Fe) is absorbed by enterocytes in the small intestine. Enterocytes export Fe into the blood; this process can be inhibited by hepcidin. Fe is then transported to the liver for storage, excretion, or distribution to other organs in the body. Fe can be excreted by the liver into bile and transported into the small intestine, where it can undergo enterohepatic circulation or can be eliminated from the body via the feces. Fe can also be excreted from the body by turnover of epithelial cells lining the intestines or from minor trauma to intestinal epithelium leading to blood loss. Dashed lines indicate minor routes of $\mathrm{Fe}$ excretion, which include blood loss, exfoliation of dead skin, and excretion via the urine. For the sake of simplicity, not all organs or pathways of Fe transport are shown, including those that mediate heme $\mathrm{Fe}$ absorption. untreated $\operatorname{Tr} f^{1 p \times / h p x}$ mice relative to those in $\operatorname{Tr}^{f^{\prime /+}}$ mice at 2.5 months of age (Online Supplementary Figure S7), the rate at which biliary iron is eliminated from the body is not only influenced by biliary iron levels. Dietary iron deficiency can alter rates of bile synthesis in rats. ${ }^{53}$ In rats, iron can also undergo enterohepatic circulation, the process by which substances excreted in bile are reabsorbed by the small intestine and transported back to the liver. ${ }^{54} \mathrm{~A}$ study of the role of hepatobiliary iron excretion would require measurement of bile synthesis rates and iron levels and rates of enterohepatic circulation in multiple animal models of iron excess and deficiency. Analysis of the biochemical form of biliary iron is also warranted, as this may indicate a potential mechanism for iron excretion. Iancu et al. observed electron-dense material within bile canaliculi similar in appearance to hemosiderin. ${ }^{55}$ This type of study, along with a study of the contribution of epithelial turnover to iron excretion, would also need to be performed in both male and female subjects given that ${ }^{59} \mathrm{Fe}$ excretion rates were decreased in untreated male but not female $\operatorname{Tr}^{4 p x / h p x}$ mice (Figure 4E).

\section{Acknowledgments}

The authors would like to thank Joseph Orchardo and David Murray for assistance with metal measurements and Iqbal Hamza and Anatoly Zhitkovich for reviewing the manuscript. This work was supported by NIH grants DK84122 and DK110049 (TBB) and GM080219 (PM).

\section{References}

1. Coffey R, Ganz T. Iron homeostasis: an anthropocentric perspective. J Biol Chem. 2017;292(31):12727-12734.

2. Dev S, Babitt JL. Overview of iron metabolism in health and disease. Hemodial Int Int Symp Home Hemodial. 2017;21 (Suppl 1)S6-S20.

3. Muckenthaler MU, Rivella S, Hentze MW, Galy B. A red carpet for iron metabolism. Cell. 2017;168(3):344-361.

4. Papanikolaou G, Pantopoulos K. Systemic iron homeostasis and erythropoiesis. IUBMB Life. 2017;69(6):399-413.

5. Wallace DF. The regulation of iron absorption and homeostasis. Clin Biochem Rev. 2016;37(2):51-62.

6. Brissot P, Cavey T, Ropert M, Guggenbuhl $\mathrm{P}$, Loréal O. Genetic hemochromatosis: pathophysiology, diagnostic and therapeutic management. Presse Med. 2017;46(12 Pt 2):e288-e295.

7. Kawabata H. The mechanisms of systemic iron homeostasis and etiology, diagnosis, and treatment of hereditary hemochromatosis. Int J Hematol. 2018;107(1):31-43.

8. Asadov C, Alimirzoeva Z, Mammadova T,
Aliyeva G, Gafarova S, Mammadov J. $\beta$ thalassemia intermedia: a comprehensive overview and novel approaches. Int J Hematol. 2018;108(1):5-21.

9. Cappellini MD, Motta I. New therapeutic targets in transfusion-dependent and -independent thalassemia. Hematol Am Soc Hematol Educ Program. 2017;2017(1):278283.

10. Gupta R, Musallam KM, Taher AT, Rivella $S$. Ineffective erythropoiesis: anemia and iron overload. Hematol Oncol Clin North Am. 2018;32(2):213-221.

11. Bu JT, Bartnikas TB. The use of hypotransferrinemic mice in studies of iron biology. Biometals. 2015;28(3):473-480.

12. Bartnikas TB, Andrews NC, Fleming MD Transferrin is a major determinant of hepcidin expression in hypotransferrinemic mice. Blood. 2011;117(2):630-637.

13. Raja KB, Pountney DJ, Simpson RJ, Peters TJ. Importance of anemia and transferrin levels in the regulation of intestinal iron absorption in hypotransferrinemic mice. Blood. 1999;94(9):3185-3192.

14. Buys SS, Martin CB, Eldridge M, Kushner JP, Kaplan J. Iron absorption in hypotransferrinemic mice. Blood. 1991;78(12):32883290.
15. Parmar JH, Mendes P. A computational model to understand mouse iron physiology and diseases. bioRxiv. 2018;323899.

16. Kautz L, Jung G, Valore EV, Rivella S, Nemeth E, Ganz T. Identification of erythroferrone as an erythroid regulator of iron metabolism. Nat Genet. 2014;46(7):678-684.

17. Stevens AR, White PL, Hegsted DM, Finch CA. Iron excretion in the mouse. J Biol Chem. 1953;203(1):161-165

18. Chappelle E, Gabrio BW, Stevens AR, Finch CA. Regulation of body iron content through excretion in the mouse. Am J Physiol. 1955;182(2):390-392.

19. Skikne BS, Whittaker P, Cooke A, Cook JD. Ferritin excretion and iron balance in humans. Br J Haematol. 1995;90(3):681687.

20. Parmar JH, Davis G, Shevchuk H, Mendes P. Modeling the dynamics of mouse iron body distribution: hepcidin is necessary but not sufficient. BMC Syst Biol. 2017;11(1): 57 .

21. Casu C, Oikonomidou PR, Chen $\mathrm{H}$, et al Minihepcidin peptides as disease modifiers in mice affected by $\beta$-thalassemia and polycythemia vera. Blood. 2016;128(2):265276. 
22. Gelderman MP, Baek JH, Yalamanoglu A, et al. Reversal of hemochromatosis by apotransferrin in non-transfused and transfused Hbbth3/+ (heterozygous b1/b2 globin gene deletion) mice. Haematologica. 2015;100(5):611-622.

23. Guo S, Casu C, Gardenghi S, et al. Reducing TMPRSS6 ameliorates hemochromatosis and $\beta$-thalassemia in mice. J Clin Invest. 2013;123(4):1531-1541.

24. Ramos E, Ruchala P, Goodnough JB, et al. Minihepcidins prevent iron overload in a hepcidin-deficient mouse model of severe hemochromatosis. Blood. 2012;120(18): 3829-3836.

25. Schmidt PJ, Toudjarska I, Sendamarai AK, et al. An RNAi therapeutic targeting Tmprss6 decreases iron overload in Hfe(-/-) mice and ameliorates anemia and iron overload in murine $\beta$-thalassemia intermedia. Blood. 2013;121(7):1200-1208.

26. Green R, Charlton R, Seftel H, et al. Body iron excretion in man: a collaborative study. Am J Med. 1968;45(3):336-353.

27. Casu C, Nemeth E, Rivella S. Hepcidin agonists as therapeutic tools. Blood. 2018;131(16):1790-1794.

28. Cheng H, Bjerknes M. Cell production in mouse intestinal epithelium measured by stathmokinetic flow cytometry and Coulter particle counting. Anat Rec. 1983;207(3):427-434.

29. Creamer B, Shorter RG, Bamforth I. The turnover and shedding of epithelial cells. I. The turnover in the gastro-intestinal tract. Gut. 1961;2110-118.

30. Williams JM, Duckworth CA, Burkitt MD, Watson AJM, Campbell BJ, Pritchard DM. Epithelial cell shedding and barrier function: a matter of life and death at the small intestinal villus tip. Vet Pathol. 2015;52(3): 445-455.

31. Pountney DJ, Konijn AM, McKie AT, et al. Iron proteins of duodenal enterocytes isolated from mice with genetically and experimentally altered iron metabolism. Br J Haematol 1999;105(4):1066-1073.

32. Oates PS, Jeffrey GP, Basclain KA, Thomas $\mathrm{C}$, Morgan EH. Iron excretion in iron-overloaded rats following the change from an iron-loaded to an iron-deficient diet. J Gastroenterol Hepatol. 2000;15(6):665-674

33. Marques TG, Chaib E, da Fonseca JH, et al. Review of experimental models for induc- ing hepatic cirrhosis by bile duct ligation and carbon tetrachloride injection. Acta Cir Bras. 2012;27(8):589-594.

34. Bláha K, Cikrt M, Nerudová J, Ponka HF Biliary iron excretion in rats following treatment with analogs of pyridoxal isonicotinoyl hydrazone. Blood. 1998;91(11): 4368-4372.

35. Goss JA, Barshes NR, Karpen SJ, Gao F-O, Wyllie S. Liver ischemia and ischemiareperfusion induces and trafficks the multispecific metal transporter Atp7b to bile duct canaliculi: possible preferential transport of iron into bile. Biol Trace Elem Res. 2008;122(1):26-41.

36. Hultcrantz R, Glaumann H. Studies on the rat liver following iron overload: biochemical studies after iron mobilization. Lab Investig. 1982;46(4):383-392.

37. Drummond GS, Rosenberg DW, Kappas A. Intestinal heme oxygenase inhibition and increased biliary iron excretion by metalloporphyrins. Gastroenterology. 1992;102(4 Pt 1):1170-1175.

38. Schümann K, Schäfer SG, Forth W. Iron absorption and biliary excretion of transferrin in rats. Res Exp Med (Berl.) 1986;186 (3):215-219.

39. Zanninelli G, Choudury R, Loréal $O$, et al. Novel orally active iron chelators (3hydroxypyridin-4-ones) enhance the biliary excretion of plasma non-transferrinbound iron in rats. J Hepatol 1997;27(1): 176-184.

40. Brissot P, Zanninelli G, Guyader D, Zeind J, Gollan J. Biliary excretion of plasma nontransferrin-bound iron in rats: pathogenetic importance in iron-overload disorders. Am J Physiol. 1994;267(1 Pt 1):G135-142.

41. Dijkstra M, Kuipers F, Smit EP, de Vries JJ, Havinga R, Vonk RJ. Biliary secretion of trace elements and minerals in the rat. Effects of bile flow variation and diurnal rhythms. J Hepatol. 1991;13(1):112-119.

42. Allain P, Leblondel G, Mauras Y. Effect of aluminum and deferoxamine on biliary iron elimination in the rat. Proc Soc Exp Biol Med. 1988;188(4):471-473.

43. Brissot P, Deugnier Y, Guyader D, et al. Iron overload and the biliary route. Adv Exp Med Biol. 1994:356277-283.

44. Hall ED, Symonds HW. The maximum capacity of the bovine liver to excrete manganese in bile, and the effects of a man- ganese load on the rate of excretion of cop per, iron and zinc in bile. Br J Nutr 1981;45(3):605-611.

45. Symonds HW, Mather DL, Hall ED Surgical procedure for modifying the duodenum in cattle to measure bile flow and the diurnal variation in biliary manganese, iron, copper and zinc excretion. Res Vet Sci. 1982;32(1):6-11.

46. Deol HS, Howell JM, Dorling PR, Symonds HW. The effect of copper and heliotrope on the composition of bile in sheep. Res Vet Sci. 1992;53(3):324-330.

47. Albers CJ, Huizenga JR, Krom RA, Vonk RJ, Gips $\mathrm{CH}$. Composition of human hepatic bile. Ann Clin Biochem. 1985;22 ( Pt 2)129132.

48. Cikrt M, Ponka P, Necas E, Neuwirt J Biliary iron excretion in rats following pyridoxal isonicotinoyl hydrazone. $\mathrm{Br}$ Haematol. 1980;45(2):275-283.

49. Gooneratne SR, Chaplin RK, Trent AM, Christensen DA. Effect of tetrathiomolybdate administration on the excretion of copper, zinc, iron and molybdenum in sheep bile. Br Vet J. 1989;145(1):62-72.

50. Lévy P, Dumont M, Brissot P, et al. Acute infusions of bile salts increase biliary excretion of iron in iron-loaded rats. Gastroenterology. 1991:101(6):1673-1679.

51. LeSage GD, Kost LJ, Barham SS, LaRusso NF. Biliary excretion of iron from hepatocyte lysosomes in the rat. A major excretory pathway in experimental iron overload. J Clin Invest. 1986;77(1):90-97.

52. Hultcrantz R, Angelin B, Björn-Rasmussen E, Ewerth S, Einarsson K. Biliary excretion of iron and ferritin in idiopathic hemochromatosis. Gastroenterology. 1989;96(6): $1539-1545$

53. Prasnicka A, Cermanova J, Hroch M, et al. Iron depletion induces hepatic secretion of biliary lipids and glutathione in rats. Biochim Biophys Acta. 2017;1862(12): 1469-1480.

54. Brissot P, Bolder U, Schteingart CD, Arnaud J, Hofmann AF. Intestinal absorption and enterohepatic cycling of biliary iron originating from plasma non-transferrin-bound iron in rats. Hepatology. 1997;25(6):1457-1461.

55. Iancu TC, Shiloh $H$, Raja KB, et al. The hypotransferrinaemic mouse: ultrastructural and laser microprobe analysis observations. J Pathol. 1995;177(1):83-94. 